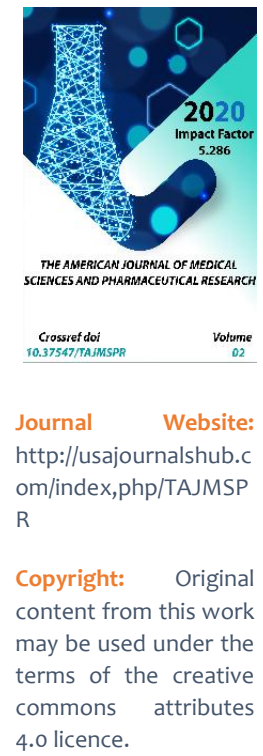

\section{Surgical Treatment Of Obliterating Arterosclerosis}

\author{
Zainiddin Norman Ugli \\ State Institution "Republican Specialized Scientific Practical Medical Center For Surgery \\ Named After Academician V. Vakhidov", Uzbekistan, 100115, Tashkent, St. Small Annular, 10. \\ Makhmudov K.O., \\ State Institution "Republican Specialized Scientific Practical Medical Center For Surgery \\ Named After Academician V. Vakhidov", Uzbekistan, 100115, Tashkent, St. Small Annular, 10. \\ Tinibekov M.X. \\ State Institution "Republican Specialized Scientific Practical Medical Center For Surgery \\ Named After Academician V. Vakhidov", Uzbekistan, 100115, Tashkent, St. Small Annular, 10.
}

\title{
ABSTRACT
}

In the literature review, according to publications of recent years, the state of surgical treatment of obliterating atherosclerosis does not meet the requirements of the time. Currently, all research is aimed at improving the early diagnosis of the disease and their timely treatment by improving the quality and efficiency of surgical intervention.

However, despite a large number of works devoted to diagnosis and prognosis of treatment, there are still many unresolved issues. The accumulated experience indicates the need to standardize the preoperative examination of patients in order to predict the outcome of treatment.

One of the important aspects of this problem is the development of modern tactics and approaches to surgical treatment. Along with them, it is necessary to evaluate the results of treatment, analyze the quality and determine the effectiveness of traditional operations in modern angiosurgery. It should be noted that today there are a considerable number of new methods of treating atherosclerosis obliterans for early and effective diagnosis, prevention and therapy of the disease.

However, some issues are insufficiently studied or contradictory and require further research.

\section{KEYWORDS}

Obliterating atherosclerosis, causes, diagnosis, surgical treatment. 
Conflict of interest. The authors declare no conflicts of interest.

Financing. The study was not sponsored.

Corresponding author: Zayniddin Norman ugli zayniddin_norman@mail.ru

For citation: Zainiddin Norman coals. Surgical treatment of obliterating atherosclerosis.

\section{INTRODUCTION}

Atherosclerosis as a systemic disease affects the arteries of all regions of the body. However, it is most commonly found in the aorta, coronary, and iliac arteries. One of the most important works was epidemiological research. According to the data, according to Bogulovsky J. et al. In patients with dominant lower limb ischemia syndrome, CA lesion was observed in $25-50 \%$, renal arteries - $10 \%$, and lesion of the branches of the aortic arch in 25 $30 \%$ of cases. At the same time, the assessment of the state of all arterial basins was carried out according to the angiographic examination data. Patients with combined lesions of several arterial pools are the most difficult category of patients, both in terms of the choice of an adequate method of surgical treatment and in relation to the results of therapeutic tactics [1] This pathology acquires social significance due to the progressive course of atherosclerotic lesions of the vascular pools and their frequent outcome in strokes causing severe disability and vascular dementia. In the domestic literature, there are isolated works on the use of spiral CT for the diagnosis of occlusive lesions of the brachiocephalic arteries and there is no information on the assessment of the importance of the main morphological substrates of atherosclerotic plaques for the prognosis of ischemic changes in the brain in the immediate and late postoperative period.

Peripheral artery disease (PAD) affects 0.5$6.9 \%$ of the population. The aortoiliac segment is involved in the occlusive process in more than half of patients with PAD (52.8\%) and the prognosis in these patients is worse than in infrainguinal lesions [2]. Progression of the occlusive process with the onset of critical limb ischemia occurs in $15-20 \%$ of cases [3] According to Verhaeghe R. (1998), the prevalence of asymptomatic peripheral arterial disease is 3-4 times higher than intermittent claudication. Pathology of the infrarenal aorta occupies one of the central places in modern angiology and is represented mainly by two forms: occlusive lesions and aneurysms. The defeat of the aorto-femoral segment occurs in more than half of cases [2]. The revealed hemodynamically significant stenosis of the aorta and iliac arteries in $52.8 \%$ of patients with PAD showed that the prognosis in these patients is worse than in those with infrainguinal lesions. The incidence of occlusive peripheral arterial disease (PAD) is difficult to establish, since the disease is asymptomatic for a long time. There are several population studies - Framingham, Basel, Edinburgh, etc., in which the frequency of intermittent claudication - the first symptom of limb ischemia - was established by a survey or clinical study [5] The prevalence of the disease was $0.5-6.9 \%$, and in the group of men over 60 years old $-7.5 \%$. On the basis of clinical data and physical research methods, with occlusive lesions of the aorto-iliac zone and the artery of the lower extremities, concomitant lesions of the branches of the 
aortic arch were found in $14-30.4 \%$ of cases $[6,7]$.

The diagnostic value of modern methods of medical imaging in the diagnosis of occlusive lesions of the brachiocephalic arteries in patients with atherosclerosis of the abdominal aorta and its branches has not been sufficiently studied, in comparison with conventional ones.

patients with atherosclerosis of the abdominal aorta and its branches, in comparison with conventional non-invasive research methods and radiopaque angiography recognized as the "gold standard". In particular, the issues of the relationship between the degree of carotid artery stenosis and the "territory" of focal ischemic lesions of the brain remain poorly understood and have not found wide application in the practice of vascular surgery.

The main non-invasive method for diagnosing carotid artery pathology today is duplex ultrasound scanning (USDS) with Doppler sonography, however, it has some limitations in its application and does not always provide accurate diagnostic data on carotid artery stenosis [8-13]. So, with the help of ultrasound Doppler ultrasound, it is rather difficult to differentiate critical stenosis from complete occlusion of the vessel. The limiting factors for the use of this method are plaque calcification, great depth of vessels, or their tortuosity. All this can affect the accuracy of the study [14]. To improve visualization of atherosclerotic plaque and assess the degree of stenosis of the carotid arteries, it is advisable to use contrast agents.

The echogenicity of carotid plaques, as shown by the results of color Doppler studies, can be used as a marker of their vulnerability [15]. For the diagnosis and prognosis of stroke, it is customary to assess the degree of stenosis of the carotid artery; however, the features of the morphology of the plaque should also be taken into account [16]. For a long time, it was believed that ulceration of an atherosclerotic plaque is the main cause of stroke development in ICA diseases [17]. Meanwhile, it is assumed that inflammatory changes and processes of neovascularization of the plaque lead to its rupture $[18,19]$.

Damage to the atherosclerotic plaque is associated with the appearance of microembolic signals (MES), which are detected during transcranial Doppler studies in patients with a history of stroke or transient ischemic attack [20]. MES are found in $43 \%$ of patients with symptoms of ICA stenosis and in $10 \%$ of patients in whom stenosis is asymptomatic [21].

Occlusive diseases and aneurysms of the infrarenal aorta and iliac arteries occupy one of the central places in modern angiosurgery. This is due to both the high prevalence of this pathology and the poor prognosis. The progression of the occlusive process with the emergence of critical limb ischemia occurs in $15-20 \%$ of cases. In contrast to obliterating diseases, the prevalence of abdominal aortic aneurysms can be estimated more accurately according to the results of pathological studies [22].

But even in the absence of critical ischemia, the presence of an obliterating disease increases the risk of death by 2-4 times. An asymptomatic decrease in $\mathrm{ABI}$ is a reliable predictor of cardiovascular accidents. This is due to the development of atherosclerotic changes in the vessels of other basins, primarily coronary and cerebrovascular [23].

With atherosclerotic lesions of the abdominal aorta and arteries of the lower extremities, combined lesions of the brachiocephalic 
branches are observed quite often. In a number of reports, the frequency of such combinations reaches $50-60 \%$ [24].

To date, there are basically three techniques in minimally invasive surgery of the aorto-iliac segment - "total" video laparoscopy, laparoscopically assisted surgery, and miniaccess.

There is also an opinion that a mini-access should be considered an incision that allows manipulation in a wound only in an apodactyl manner, i.e. without introduction of the surgeon's hand into the wound, "remotely" $[25,26]$.

It is recognized that endovideosurgical techniques are characterized by increased complexity. This leads to an increase in the duration of the operation, a high access conversion rate, which reaches $30 \%$. Special instrumentation is required; the surgeon is required to have high manual skills in endosurgery [27].

The role of multiple associated lesions in surgical treatment is increasing. Reconstruction of one of the vascular basins can lead to serious complications from other vascular basins in case of their stenosing lesion. So, mortality is noted after reconstructive vascular surgery on the lower limbs without coronary artery disease - 0.5\% and with coronary artery disease - $2.4 \%$ in patients.

Patients with obliterating disease after amputation are poorly rehabilitated. Even in the United States, only 32-42\% of patients after amputation are able to use prostheses, only 21-29\% move outside the home, and their three-year survival rate is 55\% [28]. Russian data are even more pessimistic - $68 \%$ of patients die after amputation within 2 years.
According to different authors, significant differences in the frequency of BCA lesions detection in patients with atherosclerosis of the abdominal aorta and lower limb arteries can be explained by a number of factors: 1) studies were carried out by non-invasive methods (USDG, DS) and aorto-angiography; 2) when assessing the hemodynamic significance of BCA lesions, various criteria were used from more than $50 \%$ to $75 \%$ of narrowing of the artery of interest. In the group of patients with multifocal atherosclerosis, a combination of atherosclerotic stenotic lesions of BCA and abdominal aortic aneurysms occupies a special place [29].

Abdominal aortic aneurysms (AAA) are detected in $5-6 \%$ of men over the age of 64 [30] and in $1 \%$ of women in the same age group [31]. The risk of aneurysm rupture reaches $32.5 \%$ per year with a diameter of $7 \mathrm{~cm}$ [32]. Thus, $75 \%$ of patients with symptomatic aneurysms die within a year. A ruptured aneurysm is responsible for about 16,000 deaths per year in the United States [33]. This leads to high surgical activity in diseases of the infrarenal aorta. Aortic index - the number of operations on the aorta per 100 thousand population is 19.9 in Europe [34], in Russia - 8.2 (about 4000 reconstructions in Leriche syndrome and about 2000 in infrarenal aortic aneurysm) [35].

Therefore, only those minimally invasive interventions that are able to fully provide the pathophysiological essence of the operation become the method of choice. On the contrary, in cases where mini-stupas, for one reason or another, do not allow to adequately perform all stages of the operation and require a revision of the classical principles, the intervention has not yet gone beyond the framework of a clinical experiment. In this 
regard, it is necessary to consider the fundamental aspect of minimally invasive surgery - the issue of the expediency of using a specific mini-accessible operation. When analyzing the feasibility of using a minimally invasive technique, it is necessary to note two blocks of questions:

1. Is it possible to radically perform a standard surgical technique through a mini-access, is the approved operation technology and its pathophysiological essence not violated? Is the modification of the operation safe?

2. Does the proposed method have advantages (medical and / or economic) over standard access? The first set of questions can be characterized as the reproducibility of a mini-accessible operation, and the second - as its efficiency.

Reproducibility (feasibility) of manipulation, i.e. compliance with the technology of the operation according to classical principles should always be soberly and impartially assessed. Minimally invasive surgery is based on good "open" skills and must retain all the fundamentals [36].

The desire to reduce the surgical trauma, to make the surgical manipulation as "comfortable" as possible for the patient, led to the emergence of minimally invasive surgical techniques in the mid-gos of the 2oth century. They have emerged as an alternative to traditional aorto-femoral reconstructions using wide trans- or retroperitoneal access and endovascular procedures [37].

\section{CONCLUSION}

Thus, the use of modern approaches and the development of tactics, methods of treatment of obliterating vessels, and their complications are one of the urgent problems of vascular surgery that requires an early solution. Due to the inconsistency of the results of surgical treatment, it is necessary to pay special attention to diagnosis, optimization of the choice and tactics of treatment of patients. Our experience in the treatment of OA shows the need for the operative use of modern medical methods and technologies that allow for a more accurate diagnosis and prediction of the effectiveness of the results of the outcome of surgical treatment of patients. To do this, it is necessary to develop an algorithm for diagnosis and surgical treatment, as well as scientific and practical recommendations for the timely prevention of complications of OA of blood vessels. The urgency of solving this problem is predetermined by the lack of a comprehensive a diagnostic approach to identify asymptomatic lesions of the branches of the aortic arch, ischemic cerebral infarctions and their influence on the results of surgical treatment.

The authors declare no conflicts of interest.

\section{REFERENCES}

1. Bogousslavsky J., Tsiskaridze A., Devuyst G., van-Melle G. Stroke with internal carotid artery stenosis // Arch-Neurol. 2001 Apr; 58(4): 605-9.

2. Aboyans V., Fowkes F.G. et al Peripherial artery disease: epidemiology and global perspectives.Nat Rev cardial.2017; 14: 156170.

3. Engelhardt M. Critical limb ischaemia: initial treatment and predictors of amputationfree survival / M. Engelhardt, J. Boos, H. Bruijnen et.al. // Eur. J. Vasc. Endovasc. Surg. - 2012. - Vol. 43, N 1. - P. 55-61. 
4. Verhaeghe R. The aece of low-molecularweight heparin cardiovascular disease. Acta Cardiol 1998; 53(1): 15-21.

5. Selvin et al Prevalence jf and risk factors for peripherial arterial disease in the United States: Results from the National Haelth and Nutrition Examination Survey. 19992000. Circukulation 2004;110: 738-743.

6. Fokin A.A. Modern aspects of diagnostics and surgical treatment of occlusive stenotic lesions of the branches of the aortic arch. Author's abstract. diss. ... doctor honey. sciences. $M$ :, 1996: 47.

7. Konysov M.N. Surgical treatment of chronic abdominal aortic occlusion. Abstract dissertation ... doct. honey. sciences. $M$ :, 2004: 38.

8. Sidhu PS, Allan PL. The extended role of carotid artery ultrasound. Clin Radiol. 1997;52(9):643-653.

9. Sidhu PS, Allan PL. Ultrasound assessment of internal carotid artery stenosis. Clin Radiol. 1997;52(9):654-658.

10. Sidhu PS, Allan PL, Cattin F, Cosgrove DO, Davies AH, Do DD, Karakagil S, Langholz J, Legemate DA, Martegani A, Llull JB, Pezzoli C, Spinazzi A. Diagnostic efficacy of SonoVue, a second generation contrast agent, in the assessment of extracranial carotid or peripheral arteries using colour and spectral Doppler ultrasound: a multicentre study. $\mathrm{Br} J$ Radiol. 2006;79(937):44-51.

11. AbuRahma AF, Pollack JA, Robinson PA, Mullins $D$. The reliability of color duplex ultrasound in diagnosing total carotid artery occlusion. Am J Surg. 1997;174(2):185-187.

12. Bornstein NM, Beloev ZG, Norris JW. The limitations of diagnosis of carotid occlusion by Doppler ultrasound. Ann Surg. 1988;207(3):315-317.
13. Kono Y, Pinnell SP, Sirlin CB, Sparks SR, Georgy B, Wong W, Mattrey RF. Carotid arteries: contrast-enhanced US angiography - preliminary clinical experience. Radiology. 2004;230(2):561568. Epub 2003 Dec 29.

14. Alonso A., Artemis D., Hennerici MG. Molecular Imaging of Carotid Plaque Vulnerability. Cerebrovasc Dis. 2015;39:5-12.

15. Zhou Y, Xing Y, Li Y, Bai Y, Chen Y, Sun X, Zhu $Y$, Wu J. An assessment of the vulnerability of carotid plaques: a comparative study between intraplaque neovascularization and plaque echogenicity. BMC Med Imaging. 2013;13.

16. Jaff M.R, Goldmakher GV, Lev MH, Romero $J M$. Imaging of the carotid arteries: the role of duplex ultrasonography, magnetic resonance arteriography, and computerized tomographic arteriography. Vasc Med. 2008;13(4):281-292.

17. Wechsler LR. Ulceration and carotid artery disease. Stroke. 1988;19(5):650-653.

18. Saba L, Caddeo G, Sanfilippo R, Montisci R, Mallarini G. CT and ultrasound in the study of ulcerated carotid plaque compared with surgical results: potentialities and advantages of multidetector row CT angiography. AJNR Am J Neuroradiol. 2007;28(6):1061-1066.

19. Saam T, Raya JG, Cyran CC, Bochmann K, Meimarakis G, Dietrich O, Clevert DA, Frey U, Yuan C, Hatsukami TS, Werf A, Reiser MF, Nikolaou K. High resolution carotid black-blood $3 T$ MR with parallel imaging and dedicated 4-channel surface coils. J Cardiovasc Magn Reson. 2009;11:41.

20. Ritter MA, Theismann K, Schmiedel $M$, Ringelstein EB, Dittrich R. Vascularization of carotid plaque in recently symptomatic patients is associated with the occurrence of transcranial microembolic signals. 
European Journal of Neurology. 2013;20:1218-1221.

21. Ritter MA, Dittrich $\mathrm{R}$, Thoenissen $\mathrm{N}$, Ringelstein EB, Nabavi DG. Prevalence and prognostic impact of microembolic signals in arterial sources of embolism. A systematic review of the literature. J Neurol. 2008;255(7):953-961.

22. Hinterseher I, Tromp G, Kuivaniemi $H$. Genes and abdominal aortic aneurysm. Ann Vasc Surg 2011;25:388-412. 22. J Vasc Surg

23. Sprengers R.W.,Janssen K.J.M., Moll F.L.,Verhaar M.C.,Van der Graaf Y.Prediction rule for cardiovascular events and mortality in peripheral arterial disease patients: data from the prospective Second Manifestations of ARTerial disease (SMART) cohort study.J Vasc Surg. 2009 Dec; 50: 1369-1376.

24. Pokrovsky A.V., Dan V.N .., Chupin., Kharazov A.F. Anticaogulant therapy in reconstructive surgery of the femoralpopliteal-tibial segment. Angiology and vessel. Surgery. 2002; (8) 3: 102-110.

25. Belov, Yu. V. Reconstructive operations in the aorto-iliac zone from a mini-access / Yu. V. Belov, BV Fadin. - Yekaterinburg: Center "Educational Book", 2007. - 224 p.

26. Belov Yu. V., Sinyavin GV, Barinov EV, Grabuzdov AM Contrast-enhanced ultrasound as the most informative method for diagnosing instability of atherosclerotic plaque of the carotid artery.// Surgery. Journal them. N.I. Pirogov. 2018; (9): 52-56 DOI: 10.17116 / hirurgia2018090152.

27. Cochennec F. et al A comparison of total laparoscopic and open repair of abdominal aortic aneurysms. J Vasc Surg 55:1549-1553, 2012.

28. Nehler M, Joseph R Coll, William R Hiatt, Judith $G$ Regensteiner, Gabriel T Schnickel, William A Klenke, Pam K Strecker, Michelle
W Anderson, Darrell N Jones, Thomas A Whitehill, Shevie Moskowitz, William C Krupski. Functional Outcome in a Contemporary Series of Major Lower Extremity. J Vasc Surg, 2003 Jul; 38 (1): 7-14. doi: 10.1016 / s0741-5214 (03) 00092-2.

29. Ambatello S. G. Diagnostics and treatment of patients with multifocal atherosclerosis. Abstract of the dissertation of the doctor of medical sciences. Moscow, 2002.

30. Lindholt J. S, Svend Juul, Helge Fasting, Eskild W. Henneberg Screening for Abdominal Aortic Aneurysms: Single Centre Randomised Controlled Trial. Clinical Trial. 2005; 2;330(7494):750. doi: 10.1136.

31. Ferket B.S., Sproks., Calkesen E.B. et al Systimatic revtew of guidelines on peripheral artery sisease screening.Am.J.Med.2012; 125: 198-208.

32. Schlsser F.L . et al. Dissection of the abdominal aorta.Current evidence and implacations for trentment strategies: a review and meta-analysis of 92 patents. J. Endovase Thev. 2009; 16(1): 71-80.

33. Norman P.E et al C-reactive protein Levels and the eparsion of screen detected addominal aortic aneurysms in men. Circulation 2004; 110(7); 862.

34. Liopis C. Dietal what vascular surgeon should know and do about atherosclerotic risk factors. J. Vasc. Surg. 2009; 49(5); 13481354.

35. Bakeria L.A., Sh.D. Zarandia, A.A. Ozolinsh, N.A. Darvish, R.A. Abdulgasanov of successful surgical treatment of a child with hypoplasia of the proximal internal carotid artery, tortuosity of the contralateral internal carotid artery, arterial hypertension // Children's diseases of the heart and blood vessels, 2018; 15 (2) 109112. DOI: 10.24022 / 1810-0686-2018-15-2-109112 
Doi: https://doi.org/10.37547/TAJMSPR/Volume02Issue09-10

36. Angelescu N, Popa E, Burcoş T, Jitea N, Angelescu M. The Rectal Cancer--Between Resection and Amputation. Surgeon's Decalogue. Chirurgia (Bucur). Jul-Aug 2003;98(4):301-6.

37. Klokokovnik T. Application of minilaparotomy in operations for aneurysms of the abdominal aorta. Journal of Angiology and Vessel. Surgery2001; (7) 4:74. 